\title{
Virulence Phenotypes of a Worldwide Collection of Puccinia triticina from Durum Wheat
}

\author{
M. E. Ordoñez and J. A. Kolmer
}

Department of Plant Pathology, University of Minnesota, St. Paul, 55108, and United States Department of Agriculture-Agricultural Research Service, Cereal Disease Laboratory, St. Paul, MN 55108.

Accepted for publication 23 October 2006.

\section{ABSTRACT}

Ordoñez, M. E., and Kolmer, J. A. 2007. Virulence phenotypes of a worldwide collection of Puccinia triticina from durum wheat. Phytopathology 97:344-351.

A total of 78 isolates of Puccinia triticina from durum wheat from Argentina, Chile, Ethiopia, France, Mexico, Spain and the United States and 10 representative isolates of $P$. triticina from common wheat from the United States were tested for virulence phenotypes on seedling plants of 35 near-isogenic lines of Thatcher wheat. Isolates with virulence on lines with leaf rust resistance genes $L r 10, L r 14 b, L r 20, L r 22 a, L r 23, L r 33$, $L r 34, L r 41$, and $L r 44$ represented the most frequent phenotype. Cluster analysis showed that $P$. triticina from durum wheat from South America, North America, and Europe had an average similarity in virulence of
$90 \%$, whereas isolates from Ethiopia were $<70 \%$ similar to the other leaf rust isolates collected from durum wheat. Of the 11 isolates from Ethiopia, 7 were avirulent to Thatcher and all near-isogenic lines of Thatcher. The isolates from common wheat had an average similarity in virulence of $60 \%$ to all leaf rust isolates from durum wheat. $P$. triticina from durum wheat was avirulent to many $L r$ genes frequently found in common wheat. It is possible that $P$. triticina currently found on durum wheat worldwide had a single origin, and then spread to cultivated durum wheat in North America, South America, and Europe, whereas P. triticina from Ethiopia evolved on landraces of durum wheat genetically distinct from the cultivated durum lines grown in Europe and the Americas.

Additional keywords: tetraploid wheat, wheat leaf rust.
Wheat is the most widely grown crop in the world (3), and wheat leaf rust caused by Puccinia triticina Eriks. is found wherever wheat is grown (30). Common wheat (Triticum aestivum L.) and durum wheat ( $T$. turgidum L. var. durum) can suffer significant yield losses due to leaf rust, ranging from 1 to $40 \%$ (22). Resistant cultivars are the most economical and effective method to control leaf rust. More than 50 leaf rust resistance genes have been described in wheat (25). However, the genetic basis of resistance to $P$. triticina in durum wheat has not been as widely studied and understood as in common wheat (12). Resistance genes in durum wheat can be dominant or recessive and are inherited in a Mendelian fashion (28,36-39); however, it is not generally known if the tetraploid durum wheat (AABB) shares the same resistance genes with the hexaploid common wheat (AABBDD) in the $\mathrm{A}$ and $\mathrm{B}$ genomes or if the genes are completely distinct.

The use of resistant cultivars places a high selection pressure on P. triticina populations for virulent phenotypes. Common wheat cultivars with race-specific resistance genes succumb to new races of $P$. triticina in an average of 3 years (35), while durum wheat has maintained higher levels of resistance for longer periods of time. Durum wheat is widely grown in southern Europe, the Middle East, and northern Africa, with smaller areas grown in Argentina, Canada, Chile, Mexico, and the United States (4). Durum wheat cultivars released in northwestern Mexico remained resistant to $P$. triticina for nearly 25 years; however, in 2001 to 2003, a new race of the fungus with virulence to the durum cv. Altar C84 caused yield losses of US\$32 million to growers (35).

Corresponding author: J. A. Kolmer; E-mail address: jkolmer@umn.edu

DOI: 10.1094/PHYTO-97-3-0344

This article is in the public domain and not copyrightable. It may be freely reprinted with customary crediting of the source. The American Phytopathological Society, 2007.
Increased virulence of $P$. triticina on durum wheat also has been reported in Europe, particularly in France (5) and Spain (24), where farmers have had to apply fungicides extensively to reduce yield losses.

The movement of urediniospores across countries and continents has been documented for wheat rust fungi $(10,11,15)$. The introduction of new rust races or virulence phenotypes, caused by migration of spores throughout the wheat-producing regions of the world, poses a great challenge for breeders in their efforts to achieve durable resistance to the cereal rusts. Identification of virulence phenotypes in cereal rust populations is crucial for development of resistant cultivars. Since 1978, the United States Department of Agriculture-Agricultural Research Service Cereal Disease Laboratory has conducted yearly wheat leaf rust virulence surveys in the United States to monitor changes in the virulence phenotypes in the major wheat-growing areas. Studies of virulence phenotypes of $P$. triticina generally have focused on characterizing populations virulent to common wheat $(2,5,10$, $11,13,14,16,23,27)$. Recently, a few studies have examined populations with virulence to durum wheat $(5,24,34,35)$. In order to more effectively develop leaf rust resistance, knowledge of the distribution of phenotypes with virulence to durum wheat is needed. The objectives of this study were to characterize the virulence phenotypes of $P$. triticina infecting durum wheat from North America, South America, Europe, and Eastern Africa, and to compare these with races of $P$. triticina from common wheat, in order to determine their relationships and possible origins.

\section{MATERIALS AND METHODS}

P. triticina isolates. A collection of 53 samples of $P$. triticina from infected durum wheat was used in this study. Collections were obtained from the following countries and cooperators: Argentina and Chile, S. German; Ethiopia, D. Tanner; France, H. Goyeau and J. P. Hardouin; Mexico, R. Singh; Spain, A. del 
Olmo; and the United States, L. Jackson. In all, 6 samples from Argentina from 2003, 2 from Chile from 2003, 8 from Ethiopia from 2002, 15 from France from 2002 and 2003, 12 from Mexico from 2002, 8 from Spain from 2000 to 2003, and 2 from the United States from 2003 were used. From each collection, 1 to 3 single-uredinial isolates were derived, for a total of 78 $P$. triticina isolates from durum wheat. Single-uredinial isolation was carried out by inoculating urediniospores from each leaf rust collection on 7-day-old seedlings of the susceptible durum wheat cv. Local Red, which had been treated with a $0.33 \%$ solution of maleic hydrazide in order to enhance spore production. One week after inoculation, leaves were trimmed so that only one uredinium per plant remained. Urediniospores of each single uredinium were collected with a cyclone spore collector into a 00 gelatin capsule, and spray inoculated onto 7-day-old seedlings of Local Red to increase urediniospores. Seedlings were kept in plexiglass isolation chambers in the greenhouse in order to avoid crosscontamination. Also included for comparison was a diverse group of 10 isolates of representative virulence phenotypes of $P$. triticina from common wheat from the United States. Isolates from common wheat were increased on seedlings of the susceptible cv. Thatcher. All inoculated plants were grown in a greenhouse with temperatures between 18 and $25^{\circ} \mathrm{C}$ and a $16-\mathrm{h}$ photoperiod.

Virulence phenotype determination. A set of 35 near-isogenic lines of the wheat $\mathrm{cv}$. Thatcher, each carrying one leaf rust resistance gene, was used: $L r 1$, RL6003; $L r 2 a$, RL6016; $L r 2 c$, RL6047; Lr3a, RL6002; Lr3ka, RL6007; Lr3bg, RL6042; Lr9, RL6010; Lr10, RL6004; Lr11, RL6053; Lr12, RL6011; Lr13, RL6001; Lr14a, RL6013; Lr14b, RL6006; Lr15, RL6052; Lr16, RL6005; Lr17, RL6008; Lr18, RL6009; Lr19, RL6040; Lr20, RL6092; Lr21, RL6043; Lr22a, RL6044; Lr23, RL6012; Lr24, RL6064; Lr25, RL6084; Lr26, RL6078; Lr28, RL6079; Lr29, RL6080; Lr30, RL6049; Lr32, RL6086; Lr33, RL6057; Lr34, RL6058; Lr38, RL6097; Lr44, RL6147; and Lr45, RL6144. A winter wheat line with $\operatorname{Lr} 41$, KS90WGRC10, also was included. One-week-old seedlings were inoculated by atomizing a suspension of $0.5 \mathrm{mg}$ of urediniospores in $300 \mu \mathrm{l}$ of light mineral oil (Soltrol, 170; Chevron Phillips Chemical Co., Woodlands, TX) for each isolate. The plants were incubated in a dew chamber overnight and later kept in the greenhouse under the same conditions as described above until the seedlings were evaluated for infection types 10 to 12 days after inoculation. Infection types were scored using the scale described by Long and Kolmer (19), where $0=$ no macroscopic signs of infection, $;=$ no uredinia with hypersensitive necrotic or chlorotic flecks present, $1=$ small uredinia often surrounded by necrosis, $2=$ small to medium-size uredinia surrounded by chlorosis, 3 = medium-size uredinia without chlorosis or necrosis, $4=$ large uredinia without chlorosis or necrosis, $+=$ uredinia somewhat larger than normal for the infection type, and $-=$ uredinia somewhat smaller than normal for the infection type. Infection types 0 to $2+$ were recorded as an avirulent isolate, and 3 to 4 as a virulent isolate. The results obtained were based mostly on single virulence tests; however, if an infection type was not conclusive, the test was repeated. The virulence or avirulence phenotype to the single gene differentials for each isolate was converted to a binary code of 1 and 0 for subsequent analysis. Isolates also were given virulence phenotypes based on 16 near-isogenic Thatcher lines in the Prt code (19). Thatcher seedlings were included as susceptible checks in all tests. Additionally, all isolates were inoculated on a set of 24 durum wheat cultivars and lines (Arabian, Bordos 64, Bordos II 10, Botno, Gerardo 594, Glossy Hugenot, Hercules, Kubanka, Kyle, Lakota, Langdon, Leeds, Lloyds, Medora, Mindum, PI 387353, RL6089, Sceptre, Spelmar, Timpana, Vencedor, Wascana, Yavaros 79, and Zeramek) previously used in other $P$. triticina virulence studies $(9,36-39)$ and evaluated for infection types following the same procedures as for the Thatcher differential lines.
Cluster analysis. A similarity matrix of virulence phenotypes based on the simple matching coefficient was used to construct a dendrogram, using the unweighted pair group method with arithmetic means clustering method in NTSYS-pc (version 2.1; Exeter Software, Setauket, NY). A matrix of cophenetic values was generated using the COPH module in NTSYS-pc. The MXCOMP program was used to calculate the level of correlation between the cophenetic matrix with the similarity matrix, in order to determine how well the cluster analysis represented the data. Results also were visualized through a two-dimensional principal coordinate (PC) plot, by transforming the similarity matrix with DCENTER and then using the EIGEN program in NTSYS-pc to calculate principal coordinates. To measure the extent to which the PC analysis showed the pattern of relative distances among the isolates, a distance matrix was constructed from the eigenvectors using the SIMINT module in NTSys-pc, and then compared with the DCENTER matrix.

Diversity and distance measures. The diversity of virulence phenotypes and distance between populations of $P$. triticina from durum wheat and common wheat was calculated using the KOIND program (KOIND package; Biometrie und Populations Genetik, Justus-Liebig Universitat, Geissen). The diversity of virulence phenotypes within populations was measured using the Kosman index of diversity (18) and the normalized Shannon index $(32,33)$. The Kosman index was calculated as $K W(A)=A S S_{\max }(A, A) / n \lambda$, where $\mathrm{ASS}_{\max }$ is the maximum value of the sum of distances between $n$ matched pairs of isolates within population $A, n$ corresponds to the total number of isolates in $A$, and $\lambda$ is the number of differentials tested. The Shannon index of diversity was calculated as $S h(A)=-\Sigma p_{i} \ln \left(p_{i}\right) / \ln (n)$, where $p_{i}=$ frequency of the $i$ th virulence phenotype and $n=$ total number of isolates in population $A$. The Shannon index accounts for the number and frequency distribution of virulence phenotypes in the population, but does not account for similarities in virulence. The Kosman index is similar to the Shannon index in that it measures distribution of virulence phenotypes; however, it also measures the degree of similarity in virulence as a property of diversity.

The distance between the durum and common wheat leaf rust populations was calculated using the Kosman (18) distance index as $K B(A, B)=A S S_{\min }(A, B) / n \lambda$, where $A S S_{\min }$ is the minimum value of the sum of distances between $n$ matched pairs of an equal number of isolates from populations $A$ and $B$, and $\lambda$ is the number of differentials tested. The Roger's distance index (29) was calculated as $R(A, B)=0.5 \Sigma\left|p_{\mathrm{Ai}}-p_{\mathrm{Bi}}\right|$, where $p_{\mathrm{Ai}}$ and $p_{\mathrm{Bi}}$ are the frequencies of the $i$ th phenotype in populations $A$ and $B$, respectively. The Roger's index measures the difference between two populations based on frequencies of identical phenotypes. The Kosman distance index measures similarities in virulence between isolates in the two populations being compared. Calculations for all indexes were made using the bootstrap method with sample sizes of 100 with replacement and 100 replicas.

\section{RESULTS}

Virulence phenotypes. In all, 20 different virulence phenotypes were identified among 78 single-uredinial $P$. triticina isolates from durum wheat when tested on seedlings of 35 Thatcher near-isogenic differential lines (Table 1). All isolates originating from durum wheat were avirulent on differential lines with resistance genes $L r 1, L r 2 a, L r 2 c, L r 3 a, L r 3 k a$, Lr3bg, Lr9, Lr11, Lr16, Lr17, Lr18, Lr19, Lr21, Lr24, Lr25, Lr26, Lr29, Lr30, Lr32, Lr38, and Lr45, and virulent on seedlings with $L r 33$ and $L r 34$. Mesothetic infection types of flecks and sporulating uredinia were observed on lines with Lrl2 and Lrl3. Leaf rust isolates from durum wheat differed for virulence on lines with resistance genes $\operatorname{Lr10}, \mathrm{LrIHa}$, $L r 14 b, L r 15, L r 20, L r 22 a, L r 23, L r 41$, and Lr44. Isolates within a collection differed mostly for virulence to one or two 
resistance genes. Seven isolates from Ethiopia were avirulent to Thatcher and all Thatcher differentials. The isolates from common wheat in the United States had virulence phenotypes of BBBD, FBMT, MBRJ, MCDS, MJBJ, NBGS, PBDQ, PBLR, SBDG, and THBJ according to the nomenclature based on high and low infection types to 12 Thatcher lines described by Long and Kolmer $(14,19)$, with a fourth set of differentials with genes $\operatorname{LrB}, \mathrm{Lr} 10, \mathrm{Lr} 14 \mathrm{a}$, and $\mathrm{Lr} 18$. All isolates from durum wheat were virulent on the set of 24 durum wheat lines and cultivars, whereas the isolates from common wheat were virulent only on the susceptible checks PI387353 and RL6089.

Virulence frequencies. Leaf rust isolates from durum wheat and the isolates from common wheat differed greatly for virulence to the Thatcher lines (Table 2). Isolates from durum wheat were virulent on fewer Thatcher differential lines than the isolates from common wheat. Isolates from common wheat were virulent on 25 of 33 differential lines (virulence to $\operatorname{Lrl} 2$ and $\mathrm{Lr} 13$ were not considered), whereas isolates from durum wheat were virulent on 11 of the 33 Thatcher differential lines. Virulence frequency to genes $L r 14 a, L r 15$, and $L r 28$ was higher in the isolates from common wheat than for isolates from durum wheat. The most frequent virulence phenotype of $P$. triticina from durum wheat, found in 32 isolates, was virulent on seedlings with $\mathrm{LrlO}, \mathrm{Lrl} 4 \mathrm{~b}$, Lr20, Lr22a, Lr23, Lr33, Lr34, Lr41, and Lr44. P. triticina isolates from durum wheat had higher virulence frequencies to genes $L r 14 b, L r 22 a, L r 23, L r 33, L r 41$, and $L r 44$ than the isolates from common wheat, except for the isolates from Ethiopia that were avirulent to Thatcher and the isolates from Spain that had lower virulence frequencies for $L r 14 b$ and $L r 22 a$. All durum leaf rust isolates from France, Mexico, and the United States were virulent on $\mathrm{Lr} 10 ; 87.5 \%$ of isolates from Argentina and two of the three isolates from Chile were virulent on $\mathrm{Lr10}$, whereas all isolates from Ethiopia were avirulent on $\mathrm{Lr} 10$. Virulence frequencies on $\operatorname{Lr} 20$ were similar among durum and common wheat leaf rust isolates, ranging from 87.5 to $100 \%$, except for $7(63.4 \%)$ of the isolates from Ethiopia that were avirulent to Thatcher.

Cluster analysis. Because all isolates tested were avirulent on $\operatorname{Lr} 9, \operatorname{Lr} 19, \operatorname{Lr} 21, \operatorname{Lr} 29, \operatorname{Lr} 32$, and $\operatorname{Lr} 38$, these were not considered in the analysis. Three major groups could be distinguished (Fig. 1) within the isolates from durum wheat: isolates in group I, which had an average similarity of $90 \%$, included isolates from Argentina, Chile, France, Mexico, Spain, and the United States; isolates in group II, which had an average similarity of $84 \%$, included isolates from Ethiopia that were virulent on Thatcher (E7.1, E7.2, E7.3, and E17.4), the common wheat leaf rust isolate BBBD, and isolate A6.1 from Argentina; isolates in group III, which were $100 \%$ similar, included the Ethiopian isolates avirulent to all the Thatcher lines (E1.1, E4.1, E6.1, E10.4, E11.1, E16.1, and E16.4). The isolates in group III had an average similarity of $<78 \%$ with isolates in group II and $<70 \%$ similarity with isolates in group I. All isolates from common wheat were in group IV, except for isolate $\mathrm{BBBD}$, and had an average similarity of $60 \%$ with the isolates from durum wheat. The cophenetic correlation of the

TABLE 1. Virulence phenotypes of Puccinia triticina isolates collected from durum wheat (Argentina, Chile, Ethiopia, France, Mexico, Spain, and the United States) and from common wheat tested on seedling plants of 35 Thatcher wheat near-isogenic lines differing in leaf rust resistance genes ${ }^{\mathrm{x}}$

\begin{tabular}{|c|c|c|c|}
\hline Collection & Virulence $(L r \text { genes })^{\mathrm{y}}$ & Number of isolates & Total \\
\hline \multirow[t]{5}{*}{ Argentina } & $10,14 \mathrm{~b}, 20,22 \mathrm{a}, 23,33,34,41,44^{\mathrm{A}}$ & 3 & $\ldots$ \\
\hline & $10,14 \mathrm{~b}, 20,22 \mathrm{a}, 23,33,34,44^{\mathrm{B}}$ & 1 & $\ldots$ \\
\hline & $10,14 \mathrm{~b}, 20,22 \mathrm{a}, 23,28,33,34,41,44$ & 1 & $\ldots$ \\
\hline & $10,14 \mathrm{a}, 14 \mathrm{~b}, 15,20,22 \mathrm{a}, 23,33,34,44$ & 1 & $\ldots$ \\
\hline & $14 \mathrm{a}, 14 \mathrm{~b}, 15,22 \mathrm{a}, 33,34,41$ & 1 & 8 \\
\hline \multirow[t]{2}{*}{ Chile $^{z}$} & $10,14 \mathrm{~b}, 20,23$ & 1 & $\ldots$ \\
\hline & $10,14 \mathrm{~b}, 20$ & 1 & $\ldots$ \\
\hline & $14 \mathrm{a}, 14 \mathrm{~b}, 15,20,33,34$ & 4 & 11 \\
\hline \multirow[t]{5}{*}{ France } & $10,14 a, 14 b, 20,22 a, 23,33,34,41,44$ & 8 & $\ldots$ \\
\hline & $10,14 \mathrm{~b}, 20,22 \mathrm{a}, 23,33,34,41,44^{\mathrm{A}}$ & 6 & $\ldots$ \\
\hline & $10,14 b, 20,22 a, 33,34,41,44$ & 2 & $\ldots$ \\
\hline & $10,14 \mathrm{a}, 14 \mathrm{~b}, 15,20,22 \mathrm{a}, 23,33,34,41,44$ & 2 & $\ldots$ \\
\hline & $10,22 \mathrm{a}, 23,33,34,41,44$ & 1 & 19 \\
\hline Mexico & $10,14 \mathrm{~b}, 20,22 \mathrm{a}, 23,33,34,41,44^{\mathrm{A}}$ & 19 & $\ldots$ \\
\hline \multirow[t]{4}{*}{ Spain } & $10,14 \mathrm{~b}, 20,23,33,34,41,44^{\mathrm{D}}$ & 3 & $\ldots$ \\
\hline & $10,14 b, 20,23,33,34,44$ & 2 & $\ldots$ \\
\hline & $10,14 \mathrm{~b}, 20,23,33,34$ & 1 & $\ldots$ \\
\hline & $10,14 \mathrm{~b}, 20,22 \mathrm{a}, 23,33,34,44^{\mathrm{B}}$ & 1 & 7 \\
\hline \multirow[t]{2}{*}{ United States } & $10,14 \mathrm{~b}, 20,22 \mathrm{a}, 23,33,34,41,44^{\mathrm{A}}$ & 4 & $\ldots$ \\
\hline & $10,14 \mathrm{~b}, 15,20,22 \mathrm{a}, 23,33,34,41,44^{\mathrm{C}}$ & 2 & 6 \\
\hline \multirow[t]{8}{*}{ Common wheat } & $12,14 \mathrm{a}, 14 \mathrm{~b}, 15,20,34$ & 1 & $\ldots$ \\
\hline & $2 \mathrm{c}, 3 \mathrm{a}, 3 \mathrm{ka}, 10,11,12,13,14 \mathrm{a}, 14 \mathrm{~b}, 15,18,20,22 \mathrm{a}, 23,28,30,33,34,44$ & 1 & $\ldots$ \\
\hline & $1,3 \mathrm{a}, 3 \mathrm{ka}, 10,11,12,13 \mathrm{14a}, 14,15,20,28,34$ & 1 & $\ldots$ \\
\hline & $1,3 \mathrm{a}, 3 \mathrm{bg}, 10,12,13,14 \mathrm{a}, 14 \mathrm{~b}, 15,20,22 \mathrm{a}, 26,34$ & 1 & $\ldots$ \\
\hline & $1,3 \mathrm{a}, 10,12,13,14 \mathrm{a}, 14 \mathrm{~b}, 15,16,20,24,28,34$ & 1 & $\ldots$ \\
\hline & $1,2 \mathrm{c}, 10,11,12,13,14 \mathrm{a}, 14 \mathrm{~b} 15,20,22 \mathrm{a}, 28,30,34,44$ & 1 & $\ldots$ \\
\hline & $1,2 \mathrm{c}, 3 \mathrm{a}, 10,13,15,17,20,22 \mathrm{a}, 23,25,28,34,45$ & 1 & $\ldots$ \\
\hline & $1,2 \mathrm{c}, 3 \mathrm{a}, 3 \mathrm{ka}, 10,13,14 \mathrm{~b}, 15,20,28,34$ & 1 & $\ldots$ \\
\hline
\end{tabular}

x Thatcher near-isogenic lines Lr1, Lr2a, Lr2c, Lr3a, Lr3ka, Lr3bg, Lr9, Lr10, Lr11, Lr12, Lr13, Lr14a, Lr14b, Lr15, Lr16, Lr17, Lr18, Lr19, Lr20, Lr21, Lr22a, Lr23, Lr24, Lr25, Lr26, Lr28, Lr29, Lr30, Lr32, Lr33, Lr34, Lr38, Lr41, Lr44, and Lr45.

${ }^{\mathrm{y}}$ Identical phenotypes are identified by uppercase letters.

${ }^{z}$ Not tested with $\operatorname{Lr} 12, \operatorname{Lr} 13, \operatorname{Lr} 19, \operatorname{Lr} 22 a, \operatorname{Lr} 25, \operatorname{Lr} 29, \operatorname{Lr} 32, \operatorname{Lr} 33, \operatorname{Lr} 34, \operatorname{Lr} 38, \operatorname{Lr} 41, \operatorname{Lr} 44$, and $\operatorname{Lr} 45$. 
dendrogram with the original similarity matrix was high, with $r=$ 0.96 .

Similar groupings of isolates were found on the twodimensional coordinate plot (Fig. 2). The first two dimensions accounted for $61.8 \%$ of the variation. Most of the isolates from durum wheat grouped together, as did most of the common wheat isolates. Isolate BBBD, with coordinates $-0.120,-0.532$, was the most distant from the rest of the isolates from common wheat and the closest to the durum isolates from Ethiopia that were virulent to Thatcher, with coordinates $-0.425,0.015$. The Ethiopian isolates avirulent to the Thatcher differentials were the most distant from all other isolates, with coordinates $-0.569,0.380$. The correlation between the double-centered matrix and the similarity matrix constructed from the eigenvectors was $r=-0.61$.

Diversity of isolates. The KOIND program used to calculate distance and diversity measures does not allow for missing data; therefore, the isolates from Chile were not included in this analysis, because data for several resistance genes was not obtained. The virulence phenotypes within the total collection of isolates from durum wheat had a Kosman $(K W)$ diversity of 0.104 , and a Shannon $(S h)$ diversity of 0.414 . The isolates from common wheat had diversities of $K W=0.307$ and $S h=$ 0.492. Diversity measures within each country where samples from durum wheat were obtained were: Argentina, $K W=0.079$, $S h=0.134$; Ethiopia, $K W=0.017, S h=0.041$; France, $K W=$ $0.050, S h=0.298$; Mexico, $K W=0.255$, $S h=0.229$; Spain, $K W=$ $0.052, S h=0.103$; and the United States, $K W=0.069, S h=0.960$. Distance indices between virulence phenotypes of isolates from durum and common wheat are shown in Table 3. The common wheat isolates differed the most from all durum isolates, with a Roger's $(R)$ index of 1.0 when compared with each durum collection, and Kosman distance $(K B)$ indices between
0.339 to 0.305 . The durum isolates from France differed the most from the other durum isolates, with $K B=0.276$ and $R=1.0$ for the Ethiopian isolates, and $K B=0.138$ and $R=0.672$ for the Mexican isolates. Isolates from the United States and Spain $(K B=$ $0.011, R=0.110)$ and the United States and Argentina $(K B=$ $0.011, R=0.087$ ) were the most similar. The overall distance between the isolates from common wheat compared with isolates collected from durum wheat was $K B=0.296$ and $R=1.0$. The average distances between isolates from each of the collections from durum wheat are shown in Table 3. Durum leaf rust isolates from France were, on average, the most distant from the other durum isolates $(K B=0.2336, R=0.8974)$, followed by isolates from Mexico $(K B=0.1244, R=0.5224)$ and Ethiopia $(K B=$ $0.1004, R=0.3842$ ).

\section{DISCUSSION}

The $P$. triticina isolates collected from durum wheat from Argentina, Chile, France, Mexico, Spain, the United States, and isolates from Ethiopia that were virulent to Thatcher had similar virulence phenotypes on Thatcher near-isogenic lines, and had very different virulence phenotypes than isolates from common wheat in the United States. Most of the durum wheat isolates from Ethiopia were avirulent to Thatcher and all differential lines tested. The results suggest that the durum isolates from Argentina, Spain, Chile, France, Mexico, and the United States had a common origin, different from that of the avirulent isolates from Ethiopia and the isolates from common wheat.

The work described here is not intended to represent an exhaustive survey of worldwide populations of $P$. triticina on durum wheat, but to present differences in pathogenicity among the pathogen populations studied in order to determine their relationships and possible origins. Diversity of virulence phenotypes of

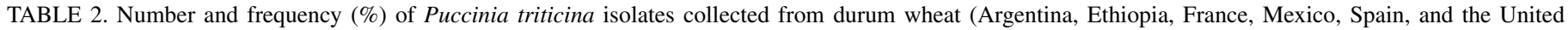
States) and common wheat from the United States virulent on 33 near-isogenic lines of Thatcher wheat

\begin{tabular}{|c|c|c|c|c|c|c|c|c|c|c|c|c|c|c|c|c|}
\hline \multirow[b]{2}{*}{ Gene } & \multicolumn{2}{|c|}{ Argentina } & \multicolumn{2}{|c|}{ Chile } & \multicolumn{2}{|c|}{ Ethiopia } & \multicolumn{2}{|c|}{ France } & \multicolumn{2}{|c|}{ Mexico } & \multicolumn{2}{|c|}{ Spain } & \multicolumn{2}{|c|}{ United States } & \multicolumn{2}{|c|}{ Common wheat } \\
\hline & No. & $\%$ & No. & $\%$ & No. & $\%$ & No. & $\%$ & No. & $\%$ & No. & $\%$ & No. & $\%$ & No. & $\%$ \\
\hline Lrl & 0 & 0 & 0 & 0 & 0 & 0 & 0 & 0 & 0 & 0 & 0 & 0 & 0 & 0 & 8 & 80.0 \\
\hline $\operatorname{Lr} 2 a$ & 0 & 0 & 0 & 0 & 0 & 0 & 0 & 0 & 0 & 0 & 0 & 0 & 0 & 0 & 2 & 20.0 \\
\hline $\operatorname{Lr} 2 c$ & 0 & 0 & 0 & 0 & 0 & 0 & 0 & 0 & 0 & 0 & 0 & 0 & 0 & 0 & 6 & 60.0 \\
\hline$L r 3 a$ & 0 & 0 & 0 & 0 & 0 & 0 & 0 & 0 & 0 & 0 & 0 & 0 & 0 & 0 & 7 & 70.0 \\
\hline $\operatorname{Lr} 9$ & 0 & 0 & 0 & 0 & 0 & 0 & 0 & 0 & 0 & 0 & 0 & 0 & 0 & 0 & 0 & 0 \\
\hline Lrl6 & 0 & 0 & 0 & 0 & 0 & 0 & 0 & 0 & 0 & 0 & 0 & 0 & 0 & 0 & 2 & 20.0 \\
\hline $\operatorname{Lr} 24$ & 0 & 0 & 0 & 0 & 0 & 0 & 0 & 0 & 0 & 0 & 0 & 0 & 0 & 0 & 1 & 10.0 \\
\hline $\operatorname{Lr} 26$ & 0 & 0 & 0 & 0 & 0 & 0 & 0 & 0 & 0 & 0 & 0 & 0 & 0 & 0 & 2 & 20.0 \\
\hline Lr3ka & 0 & 0 & 0 & 0 & 0 & 0 & 0 & 0 & 0 & 0 & 0 & 0 & 0 & 0 & 3 & 30.0 \\
\hline Lrl1 & 0 & 0 & 0 & 0 & 0 & 0 & 0 & 0 & 0 & 0 & 0 & 0 & 0 & 0 & 3 & 30.0 \\
\hline Lrl7 & 0 & 0 & 0 & 0 & 0 & 0 & 0 & 0 & 0 & 0 & 0 & 0 & 0 & 0 & 3 & 30.0 \\
\hline Lr30 & 0 & 0 & 0 & 0 & 0 & 0 & 0 & 0 & 0 & 0 & 0 & 0 & 0 & 0 & 3 & 30.0 \\
\hline Lr3bg & 0 & 0 & 0 & 0 & 0 & 0 & 0 & 0 & 0 & 0 & 0 & 0 & 0 & 0 & 2 & 20.0 \\
\hline $\mathrm{LrlO}$ & 7 & 87.5 & 2 & 66.6 & 0 & 0 & 19 & 100.0 & 24 & 100.0 & 7 & 100.0 & 6 & 100.0 & 9 & 90.0 \\
\hline $\operatorname{Lr} 14 a$ & 2 & 25.0 & 1 & 33.3 & 4 & 36.3 & 10 & 52.6 & 0 & 0 & 0 & 0 & 0 & 0 & 7 & 70.0 \\
\hline$L r 14 b$ & 8 & 100.0 & 3 & 100.0 & 4 & 36.3 & 18 & 94.7 & 23 & 95.8 & 1 & 14.3 & 6 & 100.0 & 8 & 80.0 \\
\hline $\operatorname{Lr} 15$ & 3 & 37.5 & 0 & 0 & 4 & 36.3 & 2 & 10.5 & 2 & 8.3 & 0 & 0 & 2 & 33.3 & 10 & 100.0 \\
\hline Lrl8 & 0 & 0 & 0 & 0 & 0 & 0 & 0 & 0 & 0 & 0 & 0 & 0 & 0 & 0 & 1 & 10.0 \\
\hline $\operatorname{Lr} 19$ & 0 & 0 & $\ldots$ & $\ldots$ & 0 & 0 & 0 & 0 & 0 & 0 & 0 & 0 & 0 & 0 & 0 & 0 \\
\hline $\operatorname{Lr} 20$ & 7 & 87.5 & 3 & 100.0 & 4 & 36.3 & 18 & 94.7 & 23 & 95.8 & 7 & 100.0 & 6 & 100.0 & 10 & 100.0 \\
\hline $\operatorname{Lr} 21$ & 0 & 0 & 0 & 0 & 0 & 0 & 0 & 0 & 0 & 0 & 0 & 0 & 0 & 0 & 0 & 0 \\
\hline $\operatorname{Lr} 23$ & 7 & 87.5 & 2 & 66.6 & 0 & 0 & 17 & 89.5 & 24 & 100.0 & 7 & 100.0 & 6 & 100.0 & 3 & 30.0 \\
\hline $\operatorname{Lr} 22 a$ & 8 & 100.0 & $\ldots$ & $\ldots$ & 0 & 0 & 19 & 100.0 & 22 & 91.7 & 1 & 14.3 & 6 & 100.0 & 7 & 70.0 \\
\hline $\operatorname{Lr} 25$ & 0 & 0 & $\ldots$ & $\ldots$ & 0 & 0 & 0 & 0 & 0 & 0 & 0 & 0 & 0 & 0 & 1 & 10.0 \\
\hline $\operatorname{Lr} 28$ & 1 & 12.5 & 0 & 0 & 0 & 0 & 0 & 0 & 0 & 0 & 0 & 0 & 0 & 0 & 7 & 70.0 \\
\hline $\operatorname{Lr} 29$ & 0 & 0 & $\ldots$ & $\ldots$ & 0 & 0 & 0 & 0 & 0 & 0 & 0 & 0 & 0 & 0 & 0 & 0 \\
\hline Lr32 & 0 & 0 & $\ldots$ & $\ldots$ & 0 & 0 & 0 & 0 & 0 & 0 & 0 & 0 & 0 & 0 & 0 & 0 \\
\hline Lr33 & 8 & 100.0 & $\ldots$ & $\ldots$ & 4 & 36.3 & 19 & 100.0 & 24 & 100.0 & 7 & 100.0 & 6 & 100.0 & 1 & 10.0 \\
\hline Lr34 & 8 & 100.0 & $\ldots$ & $\ldots$ & 4 & 36.3 & 19 & 100.0 & 24 & 100.0 & 7 & 100.0 & 6 & 100.0 & 10 & 100.0 \\
\hline $\operatorname{Lr} 38$ & 0 & 0 & $\ldots$ & $\ldots$ & 0 & 0 & 0 & 0 & 0 & 0 & 0 & 0 & 0 & 0 & 0 & 0 \\
\hline $\operatorname{Lr} 41$ & 8 & 75.0 & $\ldots$ & $\ldots$ & 0 & 0 & 19 & 100.0 & 24 & 100.0 & 4 & 57.1 & 6 & 100.0 & 0 & 0 \\
\hline $\mathrm{Lr} 44$ & 7 & 87.5 & $\ldots$ & $\ldots$ & 0 & 0 & 19 & 100.0 & 24 & 100.0 & 6 & 85.7 & 6 & 100.0 & 2 & 20.0 \\
\hline $\operatorname{Lr} 45$ & 0 & 0 & $\ldots$ & $\ldots$ & 0 & 0 & 0 & 0 & 0 & 0 & 0 & 0 & 0 & 0 & 1 & 10.0 \\
\hline Total & 8 & $\ldots$ & 3 & $\ldots$ & 11 & $\ldots$ & 19 & $\ldots$ & 24 & $\ldots$ & 7 & $\ldots$ & 6 & $\ldots$ & 10 & $\ldots$ \\
\hline
\end{tabular}




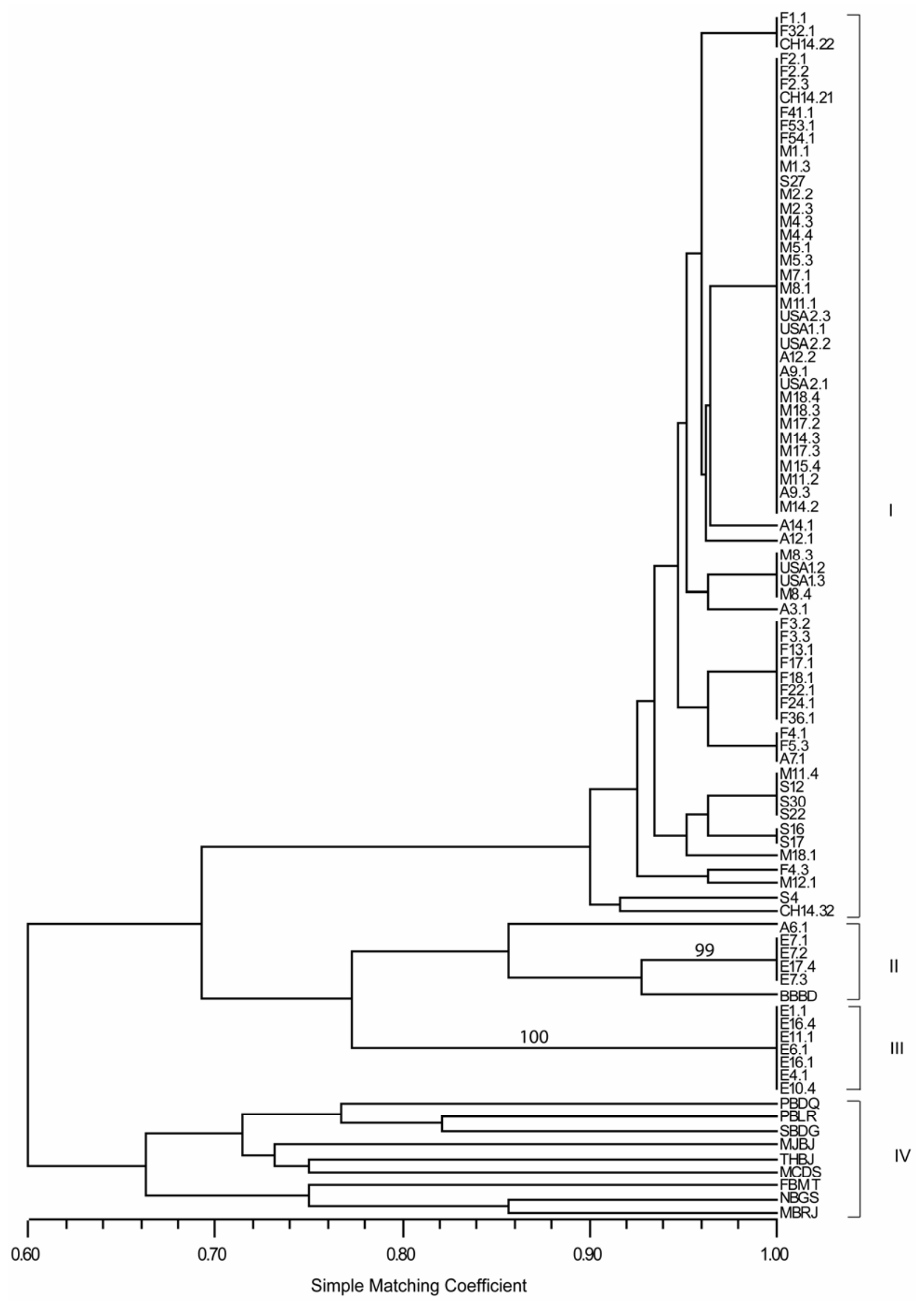

Fig. 1. Similarity dendrogram based on simple matching coefficient of 88 Puccinia triticina isolates collected from durum wheat and common wheat based on virulence or avirulence to 29 Thatcher wheat lines that differ by single leaf rust resistance genes, and to the cv. Thatcher. Numbers along the nodes are bootstrap values $>75 \%$. Vertical lines to the right define the four main clusters I, II, III, and IV. A = Argentina, $\mathrm{CH}=\mathrm{Chile}, \mathrm{E}=\mathrm{Ethiopia}, \mathrm{F}=\mathrm{France}, \mathrm{M}=\mathrm{Mexico}, \mathrm{S}=$ Spain, USA = United States. The four-letter code designates common wheat leaf rust races. 
the $P$. triticina collections from durum wheat was lower than for the isolates from common wheat, as shown by the Kosman index of diversity $(K W)$, because it considers similarities in the number and distribution of unique phenotypes in addition to similarities for virulence among the phenol-types. The Shannon index, however, showed a level of diversity in the durum wheat collections that was similar to the diversity of the isolates from common wheat. The Shannon index does not take into account similarities in virulence. Additionally, the greater number of total phenotypes within the durum isolates increaseed the Shannon index (20). High diversity values were expected for the $P$. triticina isolates from common wheat, because the isolates were selected purposefully for their different virulence phenotypes and had equal frequencies. The isolates from France and Mexico showed the highest diversity indices among the durum leaf rust pathogen collections, due to the greater total number of isolates and phenotypes in both collections. The isolates from Argentina and Spain had a number of phenotypes $( \pm 1)$ similar to that from France and Mexico, but their total number of isolates was lower, which reduced the diversity indices. The durum leaf rust isolates from France were, on average, the most distant from the other durum leaf rust isolates because four of the five virulence phenotypes, including the most frequent phenotype, that were found in France were not present in the other collections.
P. triticina isolates from durum wheat were virulent on wheat lines with resistance genes in the $\mathrm{A}$ and $\mathrm{B}$ wheat genomes, except for $L r 15$ and $L r 41$ that are in the D genome. Virulence to lines with genes Lr33 and Lr44 was common for the durum isolates; however, virulence to these genes had not been detected previously in isolates from common wheat (16). Durum isolates also were virulent on seedlings of plants with Lr22a and Lr34; however, these isolates are probably avirulent to these because both optimally express resistance in adult plants. The virulence phenotypes of the Mexican isolates in this study were the same as those reported by Singh et al. (35) for P. triticina from durum wheat in Mexico between 2001 and 2003, except for virulence on Lr11. All the isolates tested in our study had low infection types to Lrll. Singh et al. (35) used the wheat cv. Hussar with $L r l 1$ as a differential, whereas our study used a Thatcher line with Lrll. The use of different wheat stocks with Lrll and interpretation of the infection types may account for the differences in virulence to Lrll between the two studies. The Mexican isolates analyzed in this study had virulence specificities on the Thatcher nearisogenic lines identical to phenotype $\mathrm{BBB}$, which was one of the most common races of $P$. triticina on durum wheat in Mexico in the 1980s (34). The durum leaf rust collections in Mexico characterized by Singh et al. (35) were virulent to the durum cv. Altar C84. If the durum isolates from Mexico in the early 1990s and early 2000s differ for virulence to Altar C84, this difference

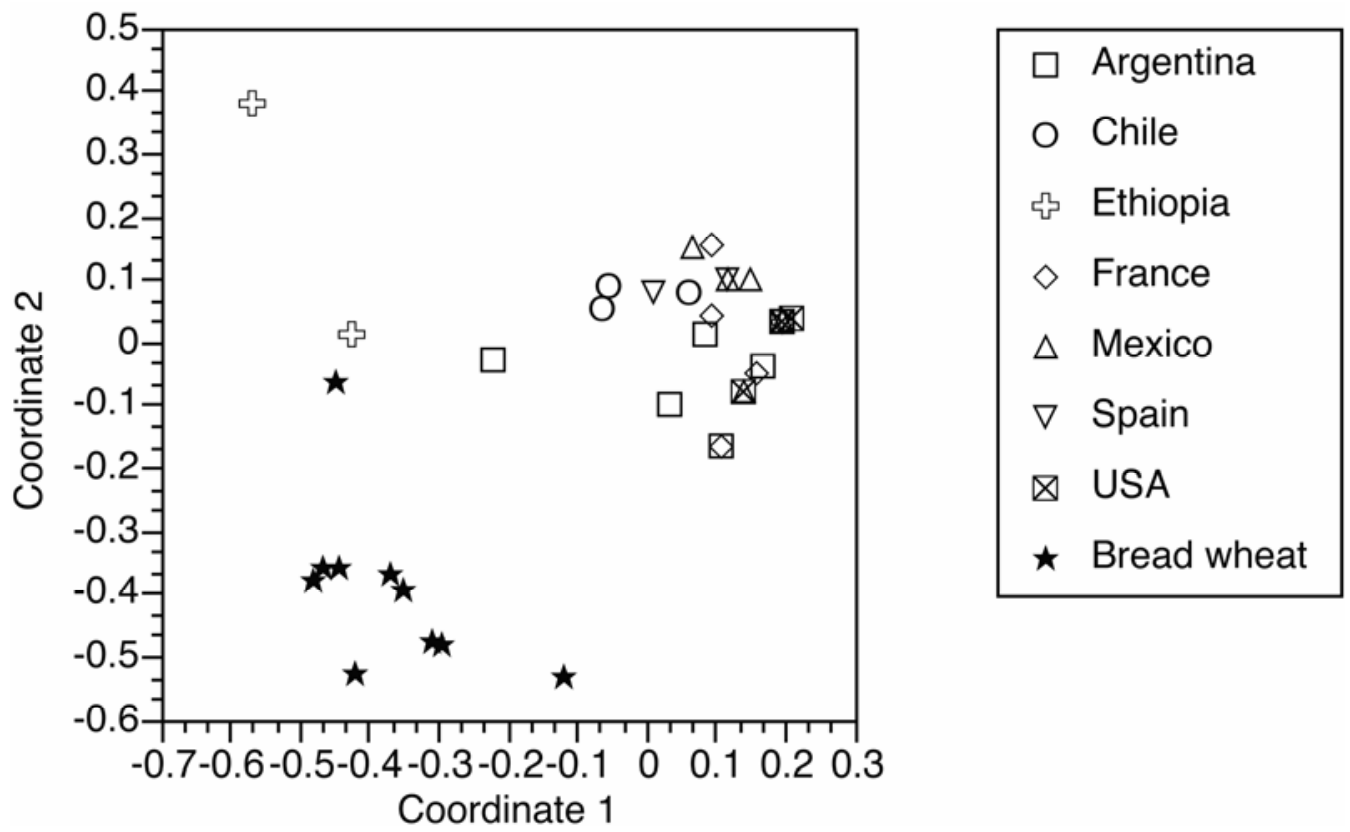

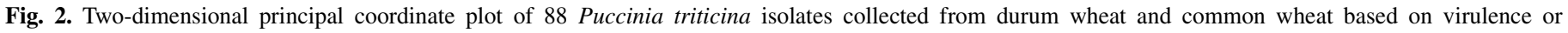
avirulence to 29 Thatcher wheat lines that differ by a single leaf rust resistance gene, and to the cv. Thatcher.

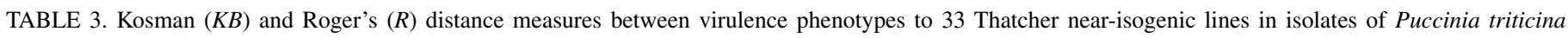
collected from durum wheat (Argentina, Ethiopia, France, Mexico, Spain, and the United States) and common wheat isolates from the United States ${ }^{\mathrm{y}}$

\begin{tabular}{|c|c|c|c|c|c|c|c|c|c|}
\hline \multirow[b]{2}{*}{ Collection } & \multirow[b]{2}{*}{ Argentina } & \multirow[b]{2}{*}{ Ethiopia } & \multirow[b]{2}{*}{ France } & \multirow[b]{2}{*}{ Mexico } & \multirow[b]{2}{*}{ Spain } & \multirow[b]{2}{*}{ United States } & \multirow[b]{2}{*}{ Common wheat } & \multicolumn{2}{|c|}{ Average $^{z}$} \\
\hline & & & & & & & & $K B$ & $R$ \\
\hline Argentina & $\ldots$ & 0.145 & 0.915 & 0.473 & 0.129 & 0.087 & 1.0 & 0.0832 & 0.3498 \\
\hline Ethiopia & 0.033 & $\ldots$ & 1.0 & 0.540 & 0.114 & 0.122 & 1.0 & 0.1004 & 0.3842 \\
\hline France & 0.246 & 0.276 & $\ldots$ & 0.672 & 0.982 & 0.918 & 1.0 & 0.2336 & 0.8974 \\
\hline Mexico & 0.111 & 0.141 & 0.138 & $\ldots$ & 0.503 & 0.424 & 1.0 & 0.1244 & 0.5224 \\
\hline Spain & 0.015 & 0.023 & 0.258 & 0.120 & $\ldots$ & 0.110 & 1.0 & 0.0854 & 0.3676 \\
\hline United States & 0.011 & 0.029 & 0.250 & 0.112 & 0.011 & $\ldots$ & 1.0 & 0.0826 & 0.3322 \\
\hline Common wheat & 0.332 & 0.351 & 0.305 & 0.311 & 0.339 & 0.335 & $\ldots$ & $\ldots$ & $\ldots$ \\
\hline
\end{tabular}

y Values above the diagonal are Roger's distance, values below the diagonal are Kosman distance.

z Average distance measures of the Kosman $(K B)$ and Roger's $(R)$ indices for isolates of $P$. triticina from durum wheat. 
probably would not be reflected in the virulence of the isolates to resistance genes in the Thatcher near-isogenic lines. The virulence specificities of $P$. triticina from durum wheat in France, described by Goyeau et al. (5), also were similar to those described here for the French isolates, except for virulence to genes $L r 2 c$ and $L r 17$, which was not found in our study. For $P$. triticina isolates from Spain, Martinez et al. (24) identified similar virulence of isolates from durum wheat, but reported virulence to $L r 2 b, L r 2 c$, and $L r 18$ that was not found on the isolates examined in our study. Those authors used an infection-type scale different than the scale used in our study for determining virulence or avirulence phenotypes. Interpretation of avirulent or virulent infection types may account for differences between the two studies. Durum and common wheat likely posses different resistance genes and, although the set of differential lines used in our study has a common wheat background, it still was useful in discriminating between the two $P$. triticina collections from durum and common wheat.

Results from cluster analyses and $K B$ and $R$ distance measures indicate that collections of $P$. triticina from durum wheat and common wheat are highly distinct for virulence phenoypes. Studies of virulence phenotypes of $P$. triticina from durum wheat in France (5), Spain (24), Mexico (34), and Israel (21) also found isolates from durum and common wheat lines to be distinct for virulence. The isolates from durum wheat are avirulent to many $\mathrm{Lr}$ genes frequently found in common wheat cultivars; thus, it is very unlikely that these isolates could survive and spread on common wheat cultivars. Selection and spread of the durum leaf rust isolates must be occurring nearly exclusively on durum wheat. The leaf rust resistance genes in durum wheat have not been characterized as fully as for common wheat. Herrera-Foessel et al. (7) identified five different sources of resistance to the durum leaf rust isolates from Mexico. It was not determined whether these genes were unique to the durum wheat lines or also were found in common wheat. The majority of isolates from durum wheat from Ethiopia were avirulent to Thatcher. This population of $P$. triticina is clearly different from the other leaf rust pathogen collections analyzed here. Huerta-Espino and Roelfs (9) also found that $78 \%$ of 210 isolates of $P$. triticina from durum wheat from Ethiopia that they analyzed were avirulent to Thatcher. Ethiopia is considered the center of diversity of the cultivated tetraploid wheat $(6,31)$. Tetraploid wheat accounts for $\approx 60 \%$ of the wheat cultivated in Ethiopia, mostly by small-scale peasant farmers who prefer to grow landraces (1). The population of $P$. triticina found there would have evolved on very different types of durum wheat than the durum wheat cultivars grown in Europe and the Americas.

The small differences in virulence specificities among the worldwide collections of $P$. triticina from durum wheat likely are due to selection and mutation, and not to introduction of different phenotypes in the same area. The durum leaf rust isolates in our study from Argentina, Chile, Mexico, France, Spain, and the United States were highly related for DNA polymorphism based on simple-sequence-repeat alleles, whereas the durum leaf rust isolates from Ethiopia and the common wheat isolates had distinct simple-sequence-repeat genotypes (26). This supports the virulence data for the hypothesis of a common origin of the durum leaf rust collections on cultivated durum wheat. The movement of $P$. triticina urediniospores across large distances could account for the wide distribution of similar virulence phenotypes of durum leaf rust. For example, $P$. triticina isolates virulent on common wheat cultivars with $\operatorname{Lr} 17$ likely were introduced to North America in the mid 1990s, and are currently a common group of leaf rust isolates in the United States (17). Similarly, in Europe, a single population of stripe rust (P. striiformis) was found in France, Germany, Denmark, and the United Kingdom according to virulence tests and DNA polymorphism (8). It is possible that isolates with increased virulence currently found on durum wheat worldwide had a single origin and spread to the cultivated durum in North America, South America, and Europe.

\section{ACKNOWLEDGMENTS}

Mention of a trademark name or proprietary product does not constitute a guarantee by the United States Department of Agriculture or the University of Minnesota. We thank M. Grabowski for laboratory and greenhouse assistance, K. Leonard for comments on the manuscript, and the Graduate School of the University of Minnesota for granting the Doctoral Dissertation Fellowship to M. E. Ordoñez to help support her studies.

\section{LITERATURE CITED}

1. Belay, G. 1997. Genetic variation, breeding potential and cytogenetic profile of Ethiopian tetraploid wheat (Triticum turgidum L.) landraces. Ph.D. thesis, Swedish University of Agricultural Sciences, Sweden.

2. Burdon, J. J., and Roelfs, A. P. 1985. Isozyme and virulence variation in asexually reproducing populations of Puccinia graminis and $P$. recondita on wheat. Phytopathology 75:907-913.

3. Curtis, B. C. 2002. Wheat in the world. Pages 1-17 in: Bread Wheat: Improvement and Production. B. C. Curtis, S. Rajaram, and H. G. Macpherson, eds. Food and Agriculture Organization of the United Nations Plant Protection Series, Rome.

4. Fabriani, G., and Lintas, C. 1988. Durum Wheat: Chemistry and Technology. American Association of Cereal Chemists, St. Paul, MN.

5. Goyeau, H., Park, R., Schaeffer, B., and Lannou, C. 2006. Distribution of pathotypes with regard to host cultivars in French wheat leaf rust populations. Phytopathology 96:264-273.

6. Harlan, J. R. 1971. Agricultural origins: centres and noncentres. Science 174:468-473.

7. Herrera-Foessel, S. A., Singh, R. P, Huerta-Espino, J., Yuen, J., and Djurle, A. 2005. New genes for leaf rust resistance in CIMMYT durum wheats. Plant Dis. 89:809-814.

8. Hovmoller, M. S., Justesen, A. F., and Brown, J. K. M. 2002. Clonality and long-distance migration of Puccinia striiformis f. sp. tritici in northwest Europe. Plant Pathol. 51:24-32.

9. Huerta-Espino, J., and Roelfs, A. P. 1992. Leaf rust on durum wheats. Vortr. Pflanzenz. 24:100-102.

10. Kolmer, J. A. 1990. Physiologic specialization of Puccinia recondita f. sp. tritici in Canada in 1989. Can. J. Plant Pathol. 12:428-430.

11. Kolmer, J. A. 1991. Evolution of distinct populations of Puccinia recondita f. sp. tritici in Canada. Phytopathology 81:316322.

12. Kolmer, J. A. 1996. Genetics of resistance to wheat leaf rust. Annu. Rev. Phytopathol. 34:435-455.

13. Kolmer, J. A. 2001. Molecular polymorphism and virulence phenotypes of the wheat leaf rust fungus Puccinia triticina in Canada. Can. J. Bot. 79:917-926.

14. Kolmer, J. A. 2003. Physiologic specialization of Puccinia triticina on wheat in the United States in 2001. Plant Dis. 87:859-866.

15. Kolmer, J. A. 2005. Tracking wheat rust on a continental scale. Curr. Opin. Plant Biol. 8:1-9.

16. Kolmer, J. A., and Liu, J. Q. 2000. Virulence and molecular polymorphism in international collections of the wheat leaf rust fungus Puccinia triticina. Phytopathology 90:427-436.

17. Kolmer, J. A., Long, D. L., and Hughes, M. E. 2004. Physiologic specialization of Puccinia triticina on wheat in the United States. Plant Dis. 88:1079-1084.

18. Kosman, E. 1996. Difference and diversity of plant pathogen populations: a new approach for measuring. Phytopathology 86:1152-1155.

19. Long, D. L., and Kolmer, J. A. 1989. A North American system of nomenclature for Puccinia recondita f. sp. tritici. Phytopathology 79:525529 .

20. Magurran, A. E. 1988. Ecological Diversity and Its Measurement. Princeton University Press, Princeton, NJ.

21. Manisterski, J., Eyal, Z., Ben-Yehuda, P., and Kosman, E. 2000. Comparative analysis of indices in the study of virulence diversity between and within populations of Puccinia recondita f. sp. tritici in Israel. Phytopathology 90:601-607.

22. Marasas, C. N., Smale, M., and Singh, R. P. 2004. The economic impact in developing countries of leaf rust resistance breeding in CIMMYT-related spring bread wheat. International Maize and Wheat 
Improvement Center, Mexico, D.F.

23. Martinez, F., Sillero, J. C., and Rubiales, D. 2004. Effect of host plant resistance on haustorium formation in cereal rust fungi. J. Phytopathol. $152: 381-382$

24. Martinez, F., Sillero, J. C., and Rubiales, D. 2005. Pathogenic specialization of Puccinia triticina in Andalusia from 1998 to 2000. J. Phytopathol. 153:344-349.

25. McIntosh, R. A., Yamazaki, Y., Devos, K. M., Dubcovsky, J., Rogers, W. J., and Appels, R. 2005. Catalogue of gene symbols for wheat. KOMUGI Integrated Wheat Science Database. Published online http://www. shigen.nig.ac.jp/wheat/komugi/genes/symbolClassList.jsp.

26. Ordoñez, M. E., Kolmer, J. A., and Szabo, L. J. 2005. Genetic diversity of a world-wide collection of Puccinia triticina from durum wheat using simple sequence repeat markers and rDNA sequence. (Abstr.) Phytopathology 95:S78.

27. Park, R. F., Jahoor, A., and Felsentstein, F. G. 2000. Population structure of Puccinia recondita in western Europe during 1995, as assessed by variability in pathogenicity and molecular markers. J. Phytopathol. 148:169-179.

28. Rashid, G., Quick, J. S., and Statler, G. D. 1976. Inheritance of leaf rust resistance in three durum wheats. Crop Sci. 16:294-296.

29. Rogers, J. S. 1972. Measures of Genetic Similarity and Genetic Distance. University of Texas Press.
30. Samborski, D. J. 1985. Wheat leaf rust. Pages 39-59 in: The Cereal Rusts. A. Roelfs and W. Bushnell, eds. Academic Press, Orlando, FL.

31. Schiemann, E. 1951. New results in the history of cultivated cereal. Heredity 5:305-320.

32. Shannon, C. E., and Weaver, W. 1949. The Mathematical Theory of Communication. University of Illinois Press, Urbana.

33. Sheldon, A. L. 1969. Equitability indices: dependence on the species count. Ecology 50:466-467.

34. Singh, R. P. 1991. Pathogenicity variations of Puccinia recondita f. sp. tritici and $P$. graminis f. sp. tritici in wheat-growing areas of Mexico during 1988 and 1989. Plant Dis. 75:790-794.

35. Singh, R. P., Huerta-Espino, J., Pfeiffer, W., and Figueroa-Lopez, P. 2004. Occurrence and impact of a new leaf rust race on durum wheat in Northwestern Mexico from 2001 to 2003. Plant Dis. 88:703-708.

36. Statler, G. D. 1973. Inheritance of leaf rust resistance in Leeds durum wheat. Crop Sci. 13:116-117.

37. Statler, G. D. 1982. Inheritance of virulence of Puccinia recondita f. sp. tritici on durum and spring wheat cultivars. Phytopathology 72:210-213.

38. Zhang, H., and Knott, D. R. 1990. Inheritance of leaf rust resistance in durum wheat. Crop Sci. 30:1218-1222.

39. Zhang, H., and Knott, D. R. 1993. Inheritance of adult plant resistance to leaf rust in six durum wheat cultivars. Crop Sci. 33:694-697. 